\title{
VARIÁVEIS CULTURAIS E PSICOSSOCIAIS ASSOCIADAS À VULNERABILIDADE ÉTNICA AO HIV/AIDS:

\author{
ESTUDO COMPARATIVO ENTRE BRASIL E FRANÇA ${ }^{\star}$
}

Andréia Isabel Giacomozzi ${ }^{\star}$

Esta Tese teve por objetivo identificar os aspectos culturais e psicossociais associados às vulnerabilidades de jovens afrodescendentes e brancos, no Brasil e na França, ao HIV/Aids. A pesquisa foi realizada em duas etapas: a primeira, qualitativa, com 36 entrevistas com estudantes do ensino médio no Brasil com o objetivo de fornecer elementos indicadores sobre a vulnerabilidade, conhecimentos e Representações Sociais da Aids dos jovens, além de indicar elementos para a elaboração de um questionário a ser aplicado na segunda etapa. E a segunda etapa, na qual foi realizado estudo quantitativo e comparativo entre Brasil e França, com 480 estudantes do ensino médio, sendo 240 de cada país, com o objetivo de comparar seu conhecimento sobre Aids, atitudes frente o preservativo, atribuições de causalidade, bem como outras variáveis psicossociais intervenientes em suas vulnerabilidades ao HIV/Aids.

Nos resultados da primeira etapa as diferenças foram mais importantes em relação ao sexo dos participantes que à etnia. As meninas são mais próximas dos doentes, e falam disso quando colocam questões sobre a Aids, enquanto os rapazes se referem principalmente aos conhecimentos mais abstratos sobre a doença. Elas se lembram da contracepção e da gravidez, enquanto eles falam principalmente de relações sexuais e amorosas. As diferenças são menos pronunciadas em termos de etnia, mas também aparecem: os afrodescendentes aparentam ter mais proximidade com os doentes que os brancos. Os brancos evocam, por outro lado, principalmente as relações amorosas, e os afrodescendentes, as relações sexuais.

Na segunda etapa, em relação à dimensão informativa, os brasileiros apresentaram mais acertos, média de 5,80 itens (dos 10 do sub-teste de conhecimento sobre Aids) do que os franceses $(4,96)$. Os participantes brancos obtiveram média de 5,59, e os afrodescendentes a média de 5,18. Quanto às fontes de informação sobre Aids, a escola, a televisão e os folhetos aparecem, como principais, sendo que para os franceses a escola é uma fonte mais importante de informação sobre Aids que para os brasileiros.

Ambos os grupos (brasileiros e franceses) apresentaram atitude favorável frente o uso do preservativo (respectivamente 3,67 e 3,45 numa escala onde o ponto médio é 3). Não havendo diferenças significativas entre etnias. Porém observou-se que as meninas têm uma atitude mais favorável que os meninos. No que concerne o uso do preservativo, os resultados ficaram homogeneamente dis-

\footnotetext{
^A Primeira etapa financiada pelo Programa de DST e Aids e UNESCO e segunda etapa financiada pelo Programa de DST e Aids e ÉGIDE - França, no âmbito da cooperação Brasil-França.

$\star \star$ Graduação, Mestrado e Doutorado em Psicologia pela Universidade Federal de Santa Catarina. Psicóloga da Secretaria Municipal de Saúde de Florianopolis.

E-mail: agiacomozzi@hotmail.com
} 
tribuídos entre os dois países, com brasileiros declarando utilizá-lo em todas as relações, mais que os franceses $(55,8 \%$ contra $45,7 \%)$, e franceses sendo maioria em declarar o não uso (26,1\% contra 19,8\%). Porém, sem associação significativa entre as proporções. Além disso, a proporção de estudantes franceses que já realizaram o teste de HIV é muito superior a dos brasileiros.

Quanto ao sentimento experimentado diante da Aids, observou-se que os brasileiros têm mais medo do que os franceses, os afrodescendentes têm mais medo que os brancos, e as meninas, mais que os meninos. Além disso, 42,5\% dos participantes declararam ter ficado bêbado nos últimos 12 meses, não havendo diferenças significativas entre os subgrupos. A declaração do uso da maconha ficou em torno de $22,7 \%$ dos participantes, com os franceses declarando ter usado mais que brasileiros $(34,7 \%$ contra $10,6 \%)$. O uso de outras drogas ficou em $11,6 \%$ não havendo diferenças significativas entre país ou etnia. 55,3\% declarou ter presenciado cenas de violência nos últimos 12 meses, com os brasileiros sendo maioria em ter presenciado cenas de violência, porém com os franceses tendo participado mais de brigas que os brasileiros.

Os resultados evidenciaram uma multiplicidade de fatores de risco às DST e ao HIV/Aids entre os jovens estudados. E essa multiplicidade varia de acordo com o grupo de pertença dos participantes, revelando desigualdades vivenciadas por membros de alguns grupos, que os expões a maior vulnerabilidade, como por exemplo, as meninas em relação aos meninos e os afrodescendentes em relação aos brancos.

Recebido em: abril de 2009

Aceito em: abril de 2009 